\title{
Ionospheric height variations observed by ionosondes along magnetic meridian and plasma bubble onsets
}

\author{
S. Saito and T. Maruyama \\ National Institute of Information and Communications Technology, Nukui-kita 4-2-1, Koganei, Tokyo 183-8795, Japan
}

Received: 11 July 2006 - Revised: 11 September 2006 - Accepted: 19 October 2006 - Published: 21 November 2006

\begin{abstract}
Since October 2004, a Frequency ModulatedContinuous Wave (FM-CW) ionosonde chain along the magnetic meridian has been operating in Southeast Asia, in Kototabang $\left(0.2^{\circ} \mathrm{S}, 100.3^{\circ} \mathrm{E}\right)$, Indonesia, Chumphon $\left(10.7^{\circ} \mathrm{N}\right.$, 99.4 $4^{\circ}$ ), Thailand, and Chiang Mai $\left(18.8^{\circ} \mathrm{N}, 98.9^{\circ} \mathrm{E}\right)$, Thailand. Variations in the virtual height of the bottomside of the F-region $\left(h^{\prime} F\right)$ at $2.5 \mathrm{MHz}$ were analyzed, in order to study the day-to-day variability of plasma bubble occurrence for the periods of October 2004 and March-April 2005. When plasma bubbles were generated, $h^{\prime} F$ was enhanced at the three stations. However, even when $h^{\prime} F$ at the equatorial station, Chumphon, was largely enhanced, plasma bubbles were not generated when a noticeable north-south asymmetry of $h^{\prime} F$ existed. This asymmetry could be attributed to the transequatorial thermospheric wind. Our results show that the strong transequatorial thermospheric wind can suppress the plasma bubble generation and is one of the important factors which controls the day-to-day variability of plasma bubble occurrences.
\end{abstract}

Keywords. Ionosphere (Equatorial ionosphere; Ionosphereatmosphere interactions; Ionospheric irregularities)

\section{Introduction}

Plasma bubbles are very dynamic phenomena in the lowlatitude and equatorial ionosphere. They are observed as intense range-type spread $\mathrm{F}$, which is defined as the non-wellbehaved diffuse traces of ionograms due to the backscatter by plasma irregularities of various scale sizes.

It is now well accepted that the fundamental mechanism of plasma bubbles is the Rayleigh-Taylor (R-T) plasma instability. It is generally known that the pre-reversal enhancement (PRE) of the zonal electric field, which uplifts the

Correspondence to: S. Saito

(susaito@nict.go.jp) ionosphere after sunset, is strong when plasma bubbles are observed. However, PRE intensity and plasma bubble occurrence do not have a one-to-one correspondence (Abdu, 2001), i.e. there are many examples of strong PRE without plasma bubbles. A number of processes are proposed to explain the variability, although no clear solution has been found.

Maruyama and Matuura (1984) found from topside sounding data that the seasonal/longitudinal variability of the equatorial spread $\mathrm{F}$ (ESF) occurrences is controlled by the latitudinal distribution of electron densities such that ESF tends to occur when the electron density distribution is symmetric with respect to the magnetic equator. They proposed that transequatorial thermospheric neutral winds might suppress the growth rate of the R-T instability. Maruyama (1988) confirmed this hypothesis by numerical calculation and showed that an increase in Pedersen conductivity, due to a lowering of the ionospheric height in the leeward hemisphere, results in a decrease in the growth rate of the R-T instability (see also Maruyama, 1996). Mendillo et al. (1992) tried to explain the day-to-day variability of ESF occurrences and found that there was a north-south asymmetry in the latitudinal plasma density distribution inferred from 630-nm airglow measurements when the ALTAIR radar at Kwajalein Atoll observed plasma bubbles. In later observations from the South American sector, however, Mendillo et al. (2001) could not find noticeable differences in the transequatorial neutral wind over the magnetic equator measured by a FabryPerot interferometer with and without plasma bubble occurrence. Valladares et al. (2001) compared the plasma bubble occurrence and total electron contents (TECs) measured by a chain of receivers along the western coast of South America. They could not find any noticeable north-south asymmetry of TECs associated with a plasma bubble occurrence, either. This result was reproduced in their recent study with more GPS receiver stations and more data sets (Valladares et al., 2004). However, Lee et al. (2005) concluded that smaller

Published by Copernicus GmbH on behalf of the European Geosciences Union. 


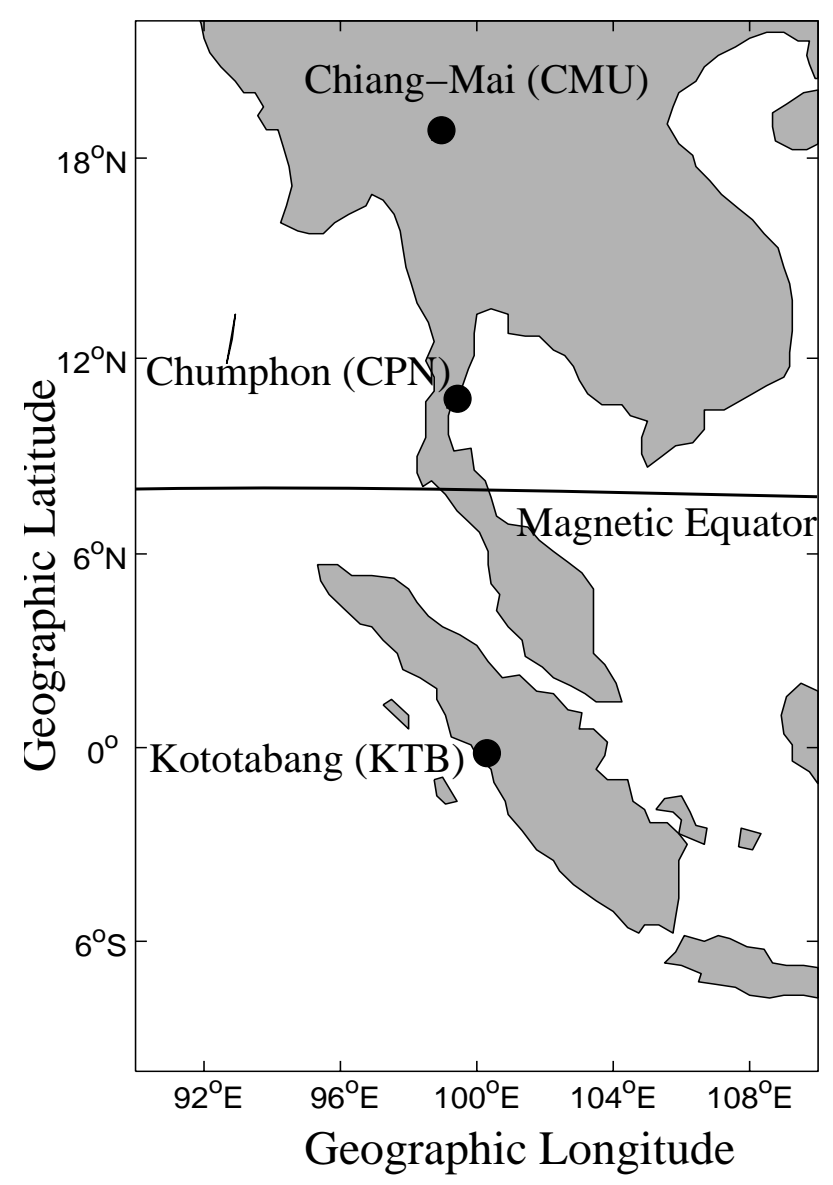

Fig. 1. Ionosonde stations locations.

north-south asymmetry and larger zonal electric fields are preferable conditions for plasma bubble onsets. Recently, Abdu et al. (2006) analyzed ionograms from two ionosonde stations, one near the magnetic equator and the other at the low latitude and found that meridional neutral wind could negatively influence the plasma bubble development. Therefore, there are continuing discussions on whether transequatorial thermospheric wind is a key factor in plasma bubble onsets.

From ionospheric height variations at three stations, one at the magnetic equator, and the others at the low-latitude regions, which are magnetically conjugate in the same magnetic meridian, it is possible to distinguish the electric field and meridional neutral wind effects with their polarity, transequatorial southward, northward, equatorward, or poleward (Maruyama, 1996). For this purpose, ionosondes were installed in Southeast Asia. In the present study, we investigate the effect of the transequatorial thermospheric neutral wind on the day-to-day variability of plasma bubble occurrences.

\section{Experiment}

The Southeast Asia Low Latitude Ionosphere Observation Network (SEALION) currently consists of three ionosondes by the National Institute of Information and Communications Technology, Japan. The locations of the stations are summarized in Fig. 1 and Table 1. They are located along the same magnetic meridian. Chumphon is located near the magnetic equator, while Chiang Mai and Kototabang are located near the magnetic conjugate points at low latitudes. Since late September 2004, all three stations have continuously been operating with some interruption due to system troubles. The observation parameters are summarized in Table 2 . The ionosondes continuously transmit radio waves from 2 to $30 \mathrm{MHz}$ and receive echoes from the ionosphere to provide the bottomside plasma density profile every $5 \mathrm{~min}$. At Kototabang, the highest frequency is limited to $20 \mathrm{MHz}$, in order to avoid radio interference with other instruments at the site.

\section{Analysis and results}

The height of the ionospheric F-region is controlled by electric fields, momentum transfer with meridional neutral winds, and chemical processes. Bittencourt and Abdu (1981) showed that the variation in virtual height $\left(h^{\prime} F\right)$ of the bottom of the F-region directly scaled in ionograms provides information on the dynamic processes in the ionosphere after sunset. With sunset, the electron density in the E- and F1-regions rapidly decreases, and retardation of the sounding waves in the lower ionosphere becomes negligible. The virtual heights of the F-region $\left(h^{\prime} F\right)$ at $2.5 \mathrm{MHz}$ are close to the real heights and its measurements at the three locations are used as a measure of the meridional electron density distribution in the bottomside ionosphere. It is known that the apparent upward motion due to recombination is not negligible when $h^{\prime} F$ is lower than $300 \mathrm{~km}$ (Bittencourt and Abdu, 1981). However, $h^{\prime} F$ can still be used to discuss the vertical motion of the F-region bottomside qualitatively. The $h^{\prime} F$ at $2.5 \mathrm{MHz}$ is manually scaled every $15 \mathrm{~min}$.

Nighttime range-type ESF is observed when plasma bubbles are generated. However, it is not always the manifestation of plasma bubbles. Since plasma bubbles develop along the geomagnetic field line, rising to high altitudes over the magnetic equator, the ESF should be observed not only at the magnetic equator, but also at low-latitudes, when plasma bubbles rise to field lines connected to the low latitude F-region bottomsides. In our analysis, the ESF occurrences were checked visually every $5 \mathrm{~min}$. We postulate that ESF with the following conditions is associated with plasma bubbles: (1) the ESF irregularities are observed at all three stations (Chumphon, Chiang Mai, and Kototabang). A typical F2 peak altitude at Chumphon at 18:00 LT, prior to PRE, is $350-400 \mathrm{~km}$. The apex altitude of the magnetic 
Table 1. Ionosonde stations locations. The apex altitude is defined by an altitude of a geomagnetic field line at the magnetic equator.

\begin{tabular}{ccccc}
\hline Site & Latitude & Longitude & Magnetic Latitude & Apex altitude of $300 \mathrm{~km}$ \\
\hline Chumphon & $10.72^{\circ}$ & $99.37^{\circ}$ & $3.22^{\circ}$ & $315 \mathrm{~km}$ \\
Kototabang & $-0.20^{\circ}$ & $100.32^{\circ}$ & $-10.10^{\circ}$ & $474 \mathrm{~km}$ \\
Chiang Mai & $18.76^{\circ}$ & $98.93^{\circ}$ & $13.21^{\circ}$ & $576 \mathrm{~km}$ \\
\hline
\end{tabular}

Table 2. Observation parameters of ionosondes of SEALION.

\begin{tabular}{|c|c|}
\hline System & $\begin{array}{l}\text { Frequency Modulated-Continuous Wave (FM-CW) } \\
\text { with pseudo-random Tx/Rx switching }\end{array}$ \\
\hline Peak Tx Power & $20 \mathrm{~W}$ \\
\hline Average Tx Power & $10 \mathrm{~W}$ \\
\hline Frequency Range & 2-30 MHz (2-20 MHz at Kototabang) \\
\hline Sweep Rate & $100 \mathrm{kHz} \mathrm{s}^{-1}$ \\
\hline Sweep Repetition Period & $5 \mathrm{~min}$ \\
\hline
\end{tabular}

field line passing at an altitude of $300 \mathrm{~km}$ over Chiang Mai is $576 \mathrm{~km}$, and it is above the F-region peak, even when the equatorial ionosphere is uplifted by the PRE electric field by $100-150 \mathrm{~km}$ at the magnetic equator $(400-550 \mathrm{~km})$. Therefore, the condition (1) guarantees that the irregularities develop into the topside ionosphere; (2) the ESF irregularities are observed at Chumphon first, and at the low-latitude stations with some time delays. When ESF irregularities are only observed at the magnetic equator (Chumphon), we consider that the irregularities are confined to the bottomside and are not associated with plasma bubbles. We did not find any cases where range-type ESF was observed at Chumphon and Chiang Mai, but not at Kototabang. Plasma bubbles are known to be generated around the F-region sunset terminator at the magnetic equator and to drift eastward (Yokoyama et al., 2004). Therefore, strong range-type ESF detected between 19 and 21 LT is considered to represent "fresh" plasma bubbles generated near the observation site. ESF observed at later times is assumed to represent "fossil" plasma bubbles that are generated far away from the site. Plasma bubble onsets should be controlled by local ionospheric conditions in the magnetic meridian, because magnetic field lines are considered to be equipotential. When "fresh" plasma bubbles are observed, the background ionospheric parameters observed by our ionosonde network would indicate plasma bubble generation conditions. By contrast, when only "fossil" plasma bubbles are observed, the background ionospheric conditions would not give any information on the plasma bubble onset conditions. They should not be classified as locally generated plasma bubbles. Therefore, in our analysis, we investigate the differences in the ionospheric conditions between those corresponding to "fresh" bubble occurrence and those corresponding to "fossil" bubbles.
We analyzed continuous $h^{\prime} F$ and ESF observation data at the SEALION ionosonde stations (Fig. 1 and Table 1) in October 2004 and March-April 2005. Figure 2 shows the maximum $h^{\prime} F$ at Chumphon and $h^{\prime} F$ at Kototabang and Chiang Mai at the same time that $h^{\prime} F$ at Chumphon reached maximum. When $h^{\prime} F$ were not available, for example, due to blanketing by sporadic-E layers, they were interpolated by the nearest $h^{\prime} F$ values, if available, scaled from 5-min ionograms. The occurrence of "fresh" plasma bubbles is also indicated in the figure. It can be seen that the maximum $h^{\prime} F$ at Chumphon is higher when "fresh" plasma bubbles are observed than when they are not. Interestingly, there are occasions where "fresh" plasma bubbles are not observed even when the maximum $h^{\prime} F$ at the magnetic equator is high. The difference between the two cases, when "fresh" plasma bubbles are observed/unobserved, can be seen in $h^{\prime} F$ at the lowlatitude stations, Kototabang and Chiang Mai. This is more clearly seen in $h^{\prime} F$ at Chiang Mai in March 2005. It appears that the ionospheric F-region needs to be uplifted not only at the magnetic equator, but also at low latitudes for plasma bubbles to develop.

To see this result more clearly, the $h^{\prime} F$ variations in local time at the three stations are shown in Fig. 3. We classified the nights into strong and weak PRE by the maximum $h^{\prime} F$ at Chumphon. When it is higher than $325 \mathrm{~km}$, we determined that the PRE was strong. The threshold value, $325 \mathrm{~km}$, was chosen by examining Fig. 2, so that all "fresh" plasma bubble events except for one extreme case (on 6 October 2004) are classified as strong PRE events. When "fresh" plasma bubbles are observed, $h^{\prime} F$ is enhanced at all the stations around 20:00 LT by the strong pre-reversal enhancement (Fig. 3a). When "fresh" plasma bubbles are not observed, the enhancement of $h^{\prime} F$ at Chiang Mai appears to be suppressed, 
(a)

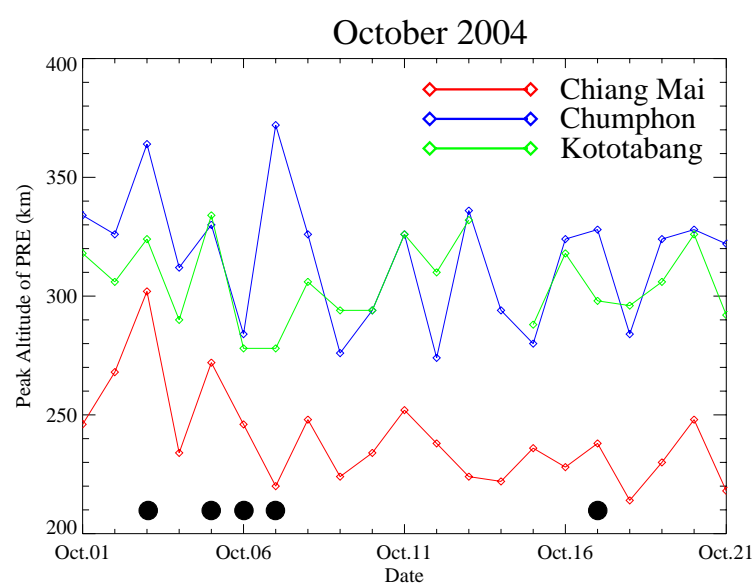

(b)

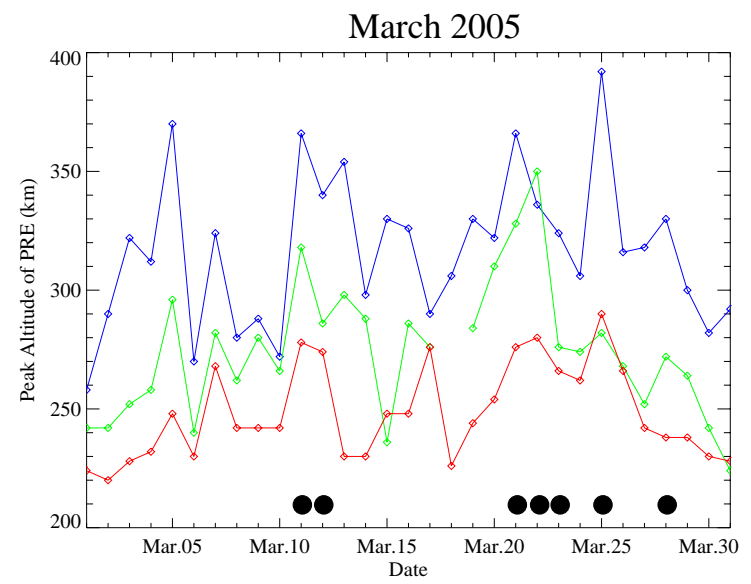

(c)

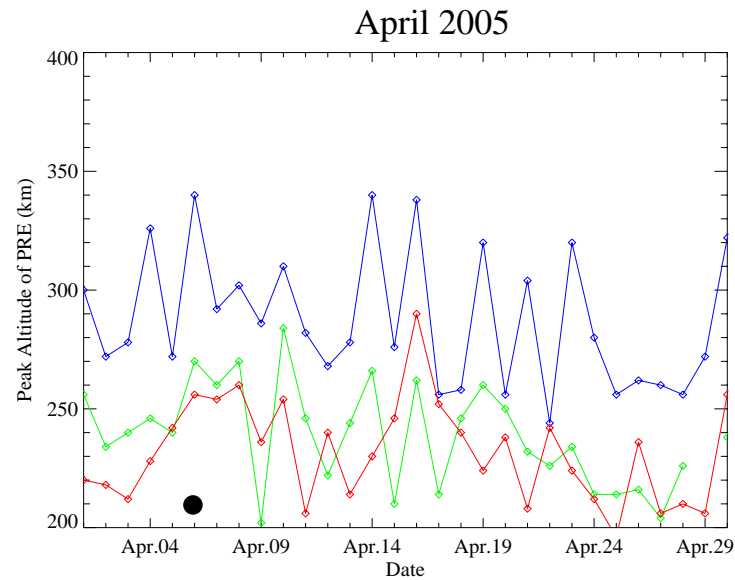

Fig. 2. Maximum $h^{\prime} F$ at Chumphon (blue line) in (a) October 2004, (b) March 2005, and (c) April 2005. The $h^{\prime} F$ at Kototabang (green) and Chiang Mai (red) at the same time that $h^{\prime} F$ at Chumphon reaches its maximum are also plotted. The solid circles indicate the occurrence of "fresh" plasma bubbles.

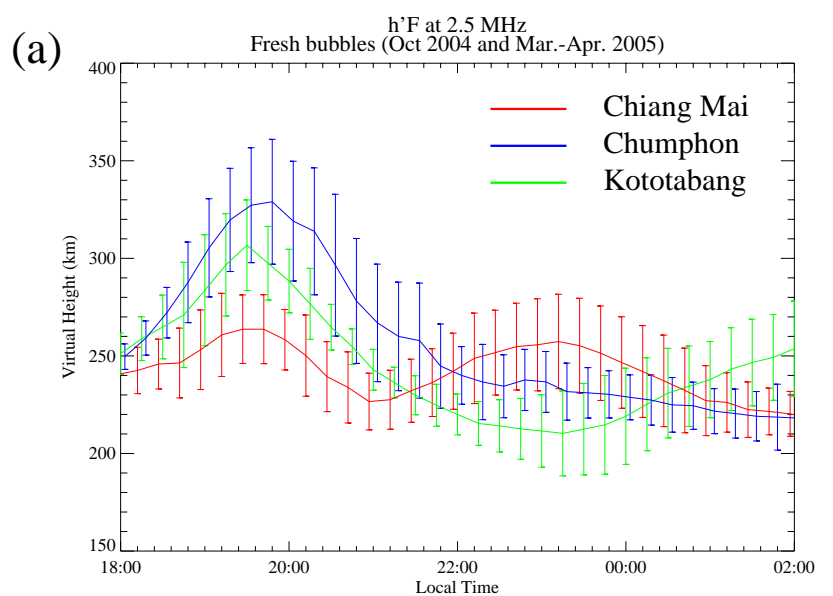

(b) No fresh bubbles (h'F(CPN) $>325$ km, Oct 2004 and Mar.-Apr. 2005)

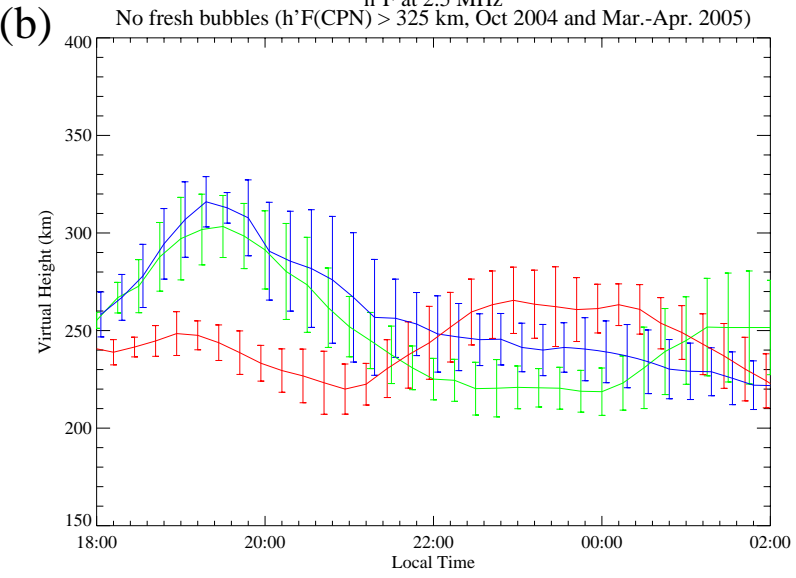

(c) No fresh bubbles (h'F(CPN) $<325$ km, Oct 2004 and Mar.-Apr. 2005)

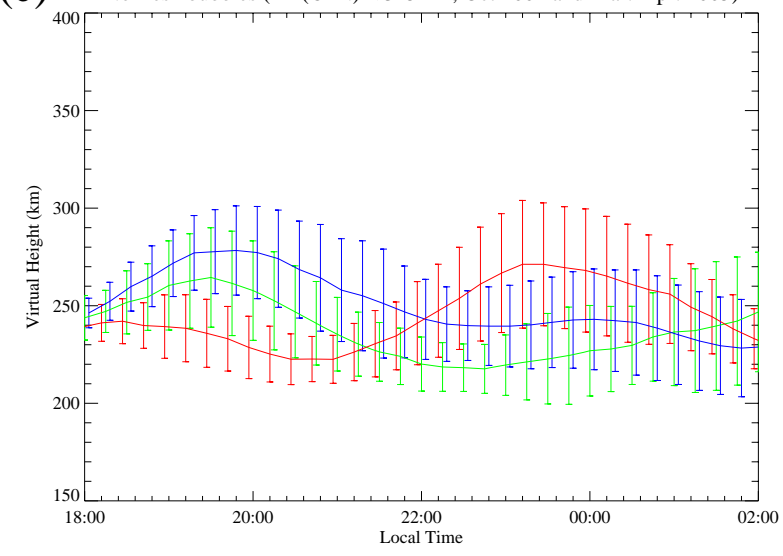

Fig. 3. $h^{\prime} F$ variations at Chumphon (blue), Kototabang (green), and Chiang Mai (red), (a) when "fresh" plasma bubbles are observed, (b) when "fresh" plasma bubbles are not observed and maximum $h^{\prime} F$ at Chumphon is higher than $325 \mathrm{~km}$, and (c) when "fresh" plasma bubbles are not observed and maximum $h^{\prime} F$ at Chumphon is lower than $325 \mathrm{~km}$. 




Fig. 4. Differences between $h^{\prime} F$ observed at Kototabang and Chiang Mai: solid line - when "fresh" plasma bubbles were observed (corresponding to Fig. 3a), and dashed line - when "fresh" plasma bubbles were not observed in spite of strong PRE (Fig. 3b). Dotted line is for all the nights used in this study.

even though $h^{\prime} F$ at Chumphon shows a strong enhancement (Fig. 3b). On the other hand, $h^{\prime} F$ at Kototabang is closer to $h^{\prime} F$ at Chumphon than in Fig. 3a, which means that $h^{\prime} F$ at Kototabang is more enhanced in a reverse sense to Chiang Mai. Figure 4 shows the mean differences between $h^{\prime} F$ at Kototabang and Chiang Mai. Figure $3 \mathrm{c}$ shows the $h^{\prime} F$ variation for the quiet condition. In the PRE period, $h^{\prime} F$ at Chiang Mai is always lower than $h^{\prime} F$ at Kototabang. This is explained as follows: Chiang Mai is located at about $3^{\circ}$ far from the magnetic equator compared with Kototabang. Both the stations are between the equatorial ionization anomaly (EIA) crests. Between EIA crests, the further away from the magnetic equator, the lower the ionospheric height. Therefore, $h^{\prime} F$ measured at a fixed frequency, $2.5 \mathrm{MHz}$, at Chiang Mai should be systematically lower than that at Kototabang. Thus, the north-south asymmetry of $h^{\prime} F$ is somewhat biased.

\section{Discussion and summary}

Our observations show that the north-south asymmetry of the ionospheric height is prominent when plasma bubbles are not observed with strong PRE compared with that when plasma bubbles are observed. Plasma bubble generation appears to be suppressed when the north-south asymmetry of the bottomside ionosphere is developed. This indicates that the height of the low-latitude F-region, and therefore, the plasma density in the low-latitude lower F-region, contributing to field-line-integrated Pedersen conductivities, is one of the key factors in determining whether plasma bubbles are generated or not.

The height of the low-latitude F-region at night is determined by both the electric fields and the meridional neutral winds, while that of the equatorial F-region is dominantly controlled by the electric fields. Since the magnetic field lines are considered to be equipotential, the contribution of the $\boldsymbol{E} \times \boldsymbol{B}$ drift on the height variations should be the same at the magnetic conjugate points. Thus, the difference in the $h^{\prime} F$ variations at the magnetic conjugate points can be attributed to the meridional neutral wind effect. We estimated the meridional wind velocities which were necessary to explain the $h^{\prime} F$ variations in Fig. 3, by the method described by Krishna Murthy et al. (1990). The estimated neutral wind velocity was about $5 \mathrm{~m} \mathrm{~s}^{-1}$ northward when "fresh" plasma bubbles were observed (Fig. 3a), and about $15 \mathrm{~m} \mathrm{~s}^{-1}$ northward when "fresh" plasma bubbles were not observed, in spite of strong PRE (Fig. 3b). It was about $5 \mathrm{~m} \mathrm{~s}^{-1}$ northward when PRE was weak (Fig. 3c), that is close to the value for "fresh" plasma bubble occurrences.

Our results indicate that the transequatorial thermospheric wind, among the other factors, is important for the suppression of the plasma bubble onsets, while several previous studies with TEC measurements in a meridional GPS receiver chain showed negative results (Mendillo et al., 2001; Valladares et al., 2001, 2004). According to Maruyama (1988, 1996), it is the height of the bottomside ionosphere, i.e. the plasma density in the lower F-region, which is important in increasing the field-line integrated Pedersen conductivity. Devasia et al. (2002) also pointed this out. The TEC is the integrated parameter and includes all the information on the electron density profile along the satellite-receiver paths. Electron densities around the F-region peak, rather than the lower F-region, contribute the most to the TEC values. Furthermore, the electron density profile around the F-region peak and at higher altitudes is determined not only by the 
meridional neutral wind, but also by the time-history of the EIA development, since daytime. Thus, we consider that the effect of the north-south symmetry/asymmetry in TECs may not necessarily be correlated with the plasma bubble occurrences.

From the point of view of space weather, it is an urgent task to predict the occurrences of plasma bubbles that cause severe scintillation in satellite waves, such as GPS signals. As seen in Fig. 3, there is large scattering in the $h^{\prime} F$ variation, indicating that there could be other factors as important for plasma bubble generation as the transequatorial thermospheric wind. However, since the transequatorial thermospheric wind turned out to be one of the important key parameters which determines the day-to-day variability of the plasma bubble occurrences, precise local neutral wind measurements are a necessary step to forecast plasma bubble occurrences.

Acknowledgement. The ionosonde stations at Chiang Mai, Chumphon, and Kototabang are operated under agreements between NICT, Japan, and Chiang Mai University, Thailand, King Mongkut's Institute of Technology Ladkrabang (KMITL), Thailand, and the Indonesian National Institute of Aeronautics and Space (LAPAN), Indonesia, respectively. The operation at Kototabang is also supported by the Equatorial Atmosphere Radar project of Kyoto University, Japan.

Topical Editor M. Pinnock thanks three referees for their help in evaluating this paper.

\section{References}

Abdu, M. A.: Outstanding problems in the equatorial ionospherethermosphere electrodynamics relevant to spread F, J. Atmos. Solar-Terr. Phys., 63, 869-884, 2001.

Abdu, M. A., Iyer, K. N., de Mederios, R. T., Batista, I. S., and Sobral, J. H. A.: Thermospheric meridional wind control of equatorial spread F and evening prereversal electric field, Geophys. Res. Lett., 33, L07106, doi:10.1029/2005GL024835, 2006.
Bittencourt, J. A., and Abdu M. A.: A theoretical comparison between apparent and real vertical ionization drift velocities in the equatorial F region, J. Geophys. Res., 86, 2451-2454, 1981.

Devasia, C. V, Jyoti, N., Subbarao, K. S. V., Viswanathan, K. S., Tiwari, D., and Sridharan, R.: On the plausible linkage of thermospheric meridional winds with the equatorial spread F, J. Atmos. Solar-Terr. Phys., 64, 1-12, 2002.

Krishna Murthy, B. V., Hari, S. S., and Somayajulu, V. V.: Nighttime equatorial thermospheric meridional winds from ionospheric $h^{\prime} F$ data, J. Geophys. Res., 95, 4307-4310, 1990.

Lee, C.-C., Liu, J.-Y., Reinisch, B. W., Chen, W.-S., and Chu, F.D.: The effects of the pre-reversal $\mathrm{E} \times \mathrm{B}$ drift, the EIA asymmetry, and magnetic activity on the equatorial spread $\mathrm{F}$ during solar minimum, Ann. Geophys., 23, 745-751, 2005,

http://www.ann-geophys.net/23/745/2005/.

Maruyama, T.: A diagnostic model for equatorial spread F, 1, Model description and application to electric field and neutral wind effects, J. Geophys. Res., 93, 14 611-14 622, 1988.

Maruyama, T.: Modeling study of equatorial ionospheric height and spread F occurrence, J. Geophys. Res., 101, 5157-5163, 1996.

Maruyama, T. and Matuura, N: Longitudinal variability of annual changes in activity of equatorial spread $\mathrm{F}$ and plasma bubbles, J. Geophys. Res., 89, 10 903-10 912, 1984.

Mendillo, M., Baumgardner, J., Pi, X. Q., Sultan, P. J., and Tsunoda, R. T.: Onset conditions for equatorial Spread F, J. Geophys. Res., 97, 13 865-13 876, 1992.

Mendillo, M., Meriwether, J., and Biondi, M.: Testing the thermospheric neutral wind suprression mechanism for day-to-day variability of equatorial spread F, J. Geophys. Res., 106, 3655-3663, 2001.

Valladares, C. E., Basu, S., Groves, K., Hagan, M. P., Hysell, D., Mazzella Jr., A. J., and Sheehan, R. E.: Measurement of the latitudinal distributions of total electron content during equatorial spread F events, J. Geophys. Res., 106, 29 133-29 152, 2001.

Valladares, C. E, Villalobos, J., Sheehan, R., and Hagan. M. P.: Latitudinal extension of low-latitude scintillations measured with a network of GPS receivers, Ann. Geophys., 22, 3155-3175, 2004, http://www.ann-geophys.net/22/3155/2004/.

Yokoyama, T., Fukao, S., and Yamamoto, M.: Relationship of the onset of equatorial $\mathrm{F}$ region irregularities with the sunset terminator observed with the Equatorial Atmosphere Radar, Geophys. Res. Lett., 31, L24804, doi:10.1029/2004GL021529, 2004. 